\title{
Spatial Distribution of Glomalin-related Soil Proteins in Coniferous and Broadleaf mixed Temperate Forest
}

\author{
Yongming WANG ${ }^{1,3,4, a}$, Chunhua J ${ }^{5, \mathrm{~b}}$, Zhaoyong $\mathrm{SHI}^{1,2,3,4 *}$, Xubin YIN ${ }^{1}$, \\ Chenzhou LIU ${ }^{1}$
}

\author{
${ }^{1}$ Henan University of Science and Technology, College of Agriculture, Luoyang, 471003, \\ China; 1030079720@qq.com; shizy1116@126.com ("correspondingauthor);397820893@qq.com;drflying@sina.com \\ ${ }^{2}$ Chinese Academy of Sciences, Key Laboratory of Mountain Surface Processes and Ecological Regulation, Chengdu 610041, China \\ ${ }^{3}$ Luoyang Key Laboratory of Plant Nutrition and Environmental Ecology, Luoyang 471003, Henan Province, China \\ ${ }^{4}$ Peking University, Laboratory for Earth Surface Processes, Ministry of Education, Beijing 100871, China \\ ${ }^{5}$ China Agricultural University, College of Resources and Environmental Sciences, Beijing 100094, China; jchlover@163.com \\ ${ }^{a, b}$ These authors contributed equally to this work
}

\begin{abstract}
Glomalin-related soil protein (GRSP), as an important component of soil organic carbon (SOC) pool, is a glycoprotein produced by the hyphae of arbuscular mycorrhizal fungi (AMF), which play a vital role in carbon and nutrient cycling in forest ecosystem. Here we investigated the spatial distribution of GRSP in plant community of the dominated species not associated with AMF based on a typical coniferous and broad-leaved temperate forest in Mt. Changbai, Northeastern China. Spatial distribution of GRSP including easily extractable GRSP (EEG) and total GRSP (TG) is represented by Moran's I on different soil depth among seven soil layers of $0-5 \mathrm{~cm}, 5-10 \mathrm{~cm}, 10-20 \mathrm{~cm}, 20-30 \mathrm{~cm}, 30-50 \mathrm{~cm}, 50-70 \mathrm{~cm}$ and $70-100 \mathrm{~cm}$. The concentrations of EEG and TG decreased with the increase of soil depth according to a logarithmic function. The Moran's $I$ coefficient of GRSP was negative in all soil layers except TG in 20-30 cm and 50-70 cm soil layers. When EEG and TG were considered, the Moran's I coefficient was positive in majority of soil layers within the separation distance of less than $4 \mathrm{~m}$ but in soil layers of $10-20 \mathrm{~cm}$ and $20-30 \mathrm{~cm}$ for EEG and in 30-50 cm for TG. The largest Moran's I coefficient including EEG and TG was observed in the soil layer of $5-10 \mathrm{~cm}$. The spatial distribution of GRSP was discrete in typical coniferous and broadleaved temperate forest, and was affected by mycorrhizal colonization rate, soil organic carbon and total nitrogen.
\end{abstract}

Keywords: arbuscular mycorrhiza; GRSP; Mt. Changbai; spatial autocorrelation; temperate forest

\section{Introduction}

Glomalin-related soil protein (GRSP) is glycoprotein produced by the hyphae of arbuscular mycorrhizal fungi (AMF) that contains large content of metal ions (Gillespie et al., 2011). GRSP is commonly found in various soils due to the ubiquitous colonization of AMF (Wright et al., 1998a; Öpik et al., 2013). The researchers have paid much attention to GRSP and AMF under global warming due to their importance in regulating soil carbon pool and slowing carbon turnover with 7-42 year (Steinberg et al., 2003; Shi et al., 2012). Meanwhile, GRSP is an important cementing agent in the formation of soil aggregates, which plays a major role in maintaining soil organic carbon (SOC) pool (Rillig et al., 2001; Wright et al., 2007), which contributed to SOC accumulation with more than 20 times higher than microbial biomass (Rillig et al., 2001; Godbold et al., 2006; Prescott, 2010; Guo, 2013). In addition, GRSP is one of the indicators of active nitrogen along with SOC (Rotter et al., 2017). The GRSP in soil is classified into the total GRSP (TG) and the easily extracted GRSP (EEG) based on the different extracted methods (Wright et al., 1998b; Rillig et al., 2001).

Spatial heterogeneity is a soil property, which exists in all kinds of characteristics such as soil aggregate (Liu et al., 2018), soil nutrient (Liu et al., 2016), soil moisture (Yang et al., 2017), etc. Therefore, it is inevitable that spatial heterogeneity also indwells on soil GRSP. He et al. (2010) showed that the dynamics of AMF and GRSP existed in high temporal and depth patterns, and was influenced by nutrient availability and enzymatic activity in $\mathrm{Mu}$ Us sandland. They also suggest that GRSP are useful indicators 
1088

for evaluating soil quality and function. Wang et al. (2017) indicated that GRSP contributed more to carbon and nutrients in deeper soils, and differently associated with climates and soil properties in vertical profiles.

Spatial autocorrelation is one of the important forms for exploring the relationship between the research object and its location in spatial, which is an important indicator to test whether the investigated parameter is associated with itself in its adjacent spatial point (Anselin, 1983; Baltagi, 2005). Spatial autocorrelation has been used in lots of studies, such as soil organic carbon (Liang et al., 2007), soil moisture (Kim, 2013), plant diversity (Kim and Shin, 2016), microbial communities atop a debris-covered glacier (Darcy et al., 2017).

In temperate forests, the dominated plants usually form symbiosis with ecto-mycorrhizal fungi (Kohmei et al., 2018), and only a few species associate with AMF (Kubisch and Hertel, 2015; Veresoglou et al., 2017), although most understory plants could form a good symbiotic relationship with AMF (Mcguire, 2007). However, AMF could change the structural composition of the community to increase the community diversity when the subordinate plants have more affinity with AMF (Urcelay and Díaz, 2003; Shi et al., 2013a; Lin et al., 2015). Therefore, the distribution of GRSP and its mechanisms have attracted much attention. Wang et al. (2018) research showed that two different pathways for affecting the pool size of GRSP in mangrove ecosystems by directly via indigenous AMF propagules or via the GRSP transport and deposition by pore water and tides. Wu et al. (2014) indicated that root and soil GRSP exhibited spatial and temporal distribution patterns in citrus rhizosphere. In this study, we try to explore (i) the spatial distribution of soil GRSP and its spatial autocorrelation and (ii) the mechanisms of the distribution based on the analysis of mycorrhizal colonization rate, soil carbon and soil $\mathrm{N}$ concentration in temperate forest ecosystem.

\section{Materials and Methods}

\section{Site description}

This study was conducted in Mt. Changbai of northeastern China. Mt. Changbai is a major mountain in Northeastern Asia, located in the northeastern part of China, at the junction of Antu county, Fusong county and Changbai county in Jilin Province, with a total area of $196465 \mathrm{~km}^{2}$ including forest of $16081 \mathrm{~km}^{2}$, grassland of $5683 \mathrm{~km}^{2}$ and the coverage rate reached $87.9 \%$ of forest(Wikipedia: https :// en. Wikipedia.org/_wiki/ Changbai_Mountain). Mt. Changbai is one of the intact natural ecosystems in China even all over the world. Furthermore, Mt. Changbai remains the large-scale native coniferous and broad-leaved mixed forest in the world, which maintains the richest biodiversity in the similar region of the northern hemisphere. The study site is a typical coniferous and broad-leaved cold temperate forest $\left(42^{\circ} 24^{\prime} \mathrm{N}, 128^{\circ} 06^{\prime} \mathrm{E}\right)$ with the characteristics of altitude of $650 \sim 750 \mathrm{~m}$, the mean annual temperature of $3.6^{\circ} \mathrm{C}$, the mean annual precipitation about $707 \mathrm{~mm}$, and the soil type of dark brown forest soil of mountain. The dominant plants include Pinus koraiensis, Betula platyphylla, Tilia amurensis,
Picea jezoensis, Abies nephrolepis, etc. are not associated with AMF (Hempel et al., 2003; Wang and Qiu, 2006; Shi et al., 2012).

\section{Sample collection}

Three $20 \mathrm{~m} \times 20 \mathrm{~m}$ plots were designed in the typical coniferous and broad-leaved forest, and each of them was divided into 25 subplots with the size of $4 \mathrm{~m} \times 4 \mathrm{~m}$. Soil samples were collected from the centre of each subplot based on seven soil depth including $0-5 \mathrm{~cm}, 5-10 \mathrm{~cm}, 10-20$ $\mathrm{cm}, 20-30 \mathrm{~cm}, 30-50 \mathrm{~cm}, 50-70 \mathrm{~cm}$ and $70-100 \mathrm{~cm}$, respectively. The roots were isolated from each soil core. The soil samples were air-dried for measuring soil organ carbon, total nitrogen, EEG and TG.

\section{Parameter analysis}

The GRSP including EEG and TG was analyzed by the method proposed by Wright (1998b). SOC was measured by organic carbon analyzer (TOCV CPH, Shimadzu, Japan). Total nitrogen (TN) was determined by elemental analyzer dry burning (Elementar Analysensysteme, $\mathrm{GmbH}$, Germany). AM colonization rate was determined according to the method described by Liu (2000) for evaluating the relationship between GRSP and AM colonization.

\section{Spatial models}

Spatial autocorrelation analysis was employed to test the attribute value of GRSP as to determine whether it was dramatically associated with its adjacent unit ( $\mathrm{Du}$ et al., 2017). This analysis method can classify into positive correlation and negative correlation, positive correlation indicating that the attribute value of a spatial unit and its adjacent unit have the same change tendency, negative correlation indicating the opposite (Sadeq et al., 2016). The commonly spatial autocorrelation index is Moran's $I$.

\section{Statistical analysis}

The changes of GSPR including EEG and TG among seven different soil layers were analyzed by ANOVA. In addition, changes with depth of soil and their relationship with soil parameters were stimulated by regression. The spatial autocorrelation of GSPR was analyzed by Geoda software. Other statistical analyses were performed in SPSS 13.0 for windows.

\section{Results}

The distribution of GRSP with the change of soil depth

Both EEG and TG decreased markedly with the increase of soil depth, and the peak values in seven soil layers were $2.516 \mathrm{mg} \mathrm{g}^{-1}$ for EEG, $3.747 \mathrm{mg} \mathrm{g}^{-1}$ for TG (Fig. 1). The EEG and TG presented the similar trend whether the changes with soil depth. When their concentrations were considered among different soil depths, the differences of EEG and TG were significant among four soil layers in the surface $0-30 \mathrm{~cm}$. However, no significant difference was observed among three soil layers in the depth of $30-100 \mathrm{~cm}$. Furthermore, the EEG and TG declined with the increase of soil depth according to a logarithmic function, which show that the changes of soil depth account for $94.67 \%$ and $93.49 \%$ for the variation of EEG and TG, respectively. 
Spatial autocorrelation of GRSP at different soil layers

The Moran's I coefficient is employed for exploring the spatial autocorrelation of GRSP in seven soil layers (Table 1). The Moran's I coefficient of EEG was negative in all soil depth', which indicate that the distributed characteristics of EEG are discrete in all seven soil layers. That is to say, EEG concentrations between two adjacent areas are not correlative. As to TG, the similar trend of Moran's I coefficient was observed in all soil depth expect for in soil layers of $20-30 \mathrm{~cm}$ and $50-70 \mathrm{~cm}$.

Further, the change characteristics with distance of EEG and TG at different soil layer were presented by global Moran's $I$ coefficient (Fig. 2). There are positive Moran's $I$ coefficient of EEG expect for $10-20 \mathrm{~cm}$ and $20-30 \mathrm{~cm}$ soil layers when the separation distance is less than $4 \mathrm{~m}$ (Fig. 2a).
There are negative or almost zero Moran's I coefficient of EEG expect $5-10 \mathrm{~cm}$ soil layer when the separation distance is less than $8 \mathrm{~m}$. When less than $12 \mathrm{~m}$ of the distance is considered, there are negative or almost zero Moran's 1 coefficient of EEG expect $20-30 \mathrm{~cm}$ and $30-50 \mathrm{~cm}$ soil layers. Further, when the distance increases to less than $16 \mathrm{~m}$, negative Moran's I coefficient is observed on EEG in the four soil layers of $5-50 \mathrm{~cm}$. There are negative Moran's I coefficient of EEG expect for in 10-20 cm soil layer when the separation distance is less than $20 \mathrm{~m}$. The changes of Moran's $I$ of TG are smaller in all soil layers during the separation distance of 0 to $16 \mathrm{~m}$ compare to between 16 and $20 \mathrm{~m}$. The largest Moran's I coefficient of TG was observed in soil layer of $5-10 \mathrm{~cm}$ when seven soil layers are considered (Fig. 2b).

Table 1. Level autocorrelation of EEG and TG

\begin{tabular}{ccc}
\hline Soil layer $/ \mathrm{cm}$ & EEG (Moran's $I)$ & TG $($ Moran's $I)$ \\
\hline $0-5$ & -0.1270 & -0.1645 \\
$5-10$ & -0.1129 & -0.0378 \\
$10-20$ & -0.1276 & -0.1445 \\
$20-30$ & -0.0455 & 0.0049 \\
$30-50$ & -0.0889 & -0.0356 \\
$50-70$ & -0.0829 & 0.0858 \\
$70-100$ & -0.0650 & -0.1060 \\
\hline
\end{tabular}
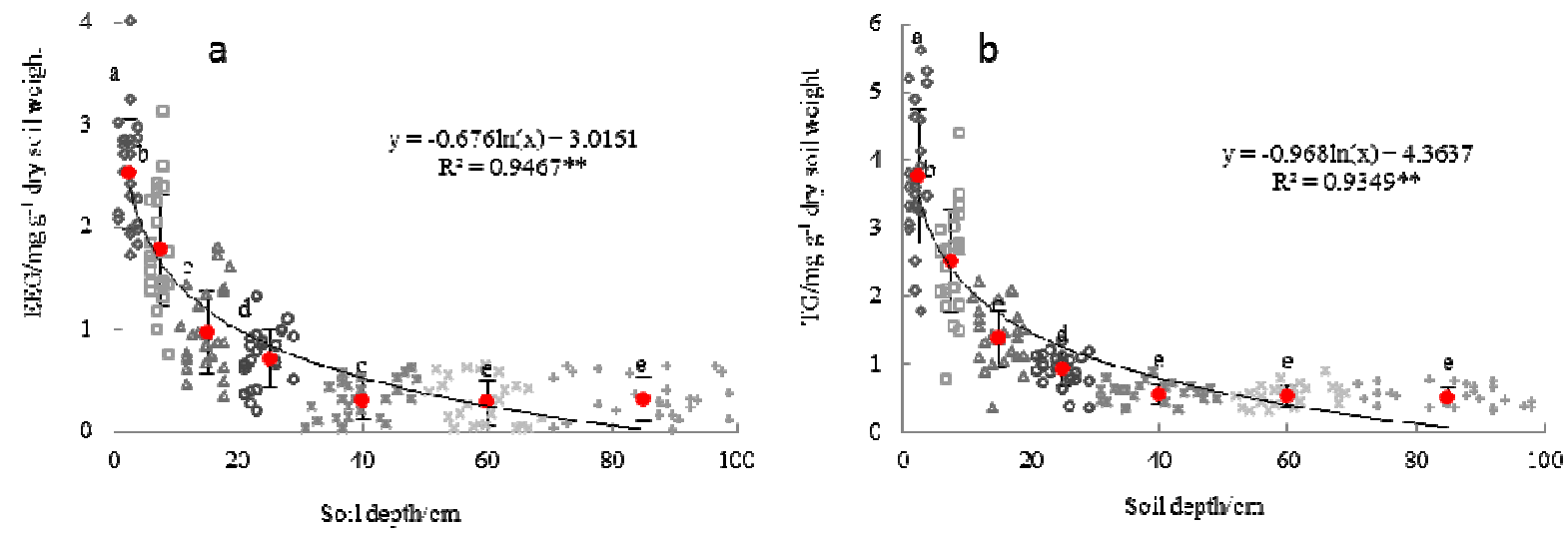

Fig. 1. The concentration of EEG (a) and TG (b) in seven different soil layer and their changes with depth of soil
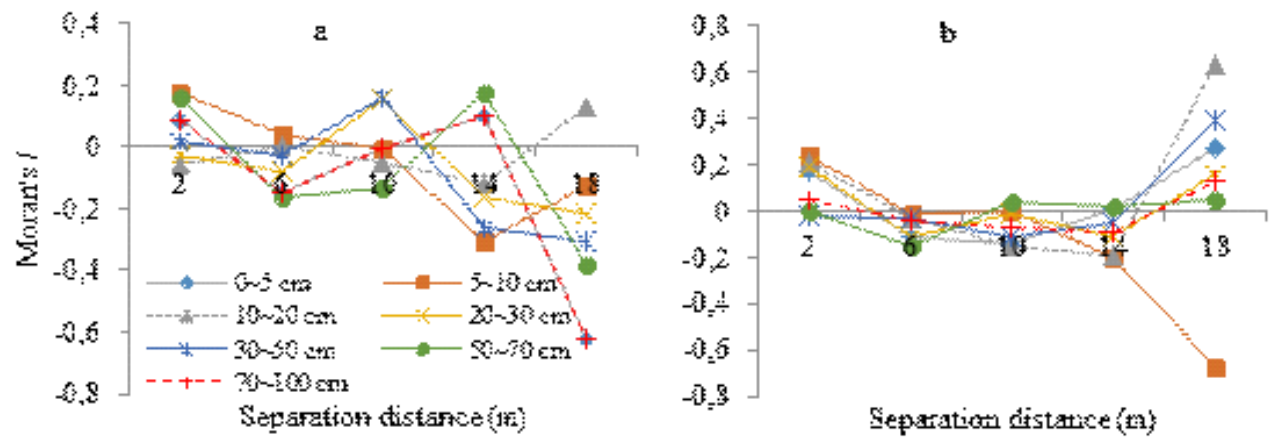

Separation distatice (m)

Fig. 2. Variation of Moran's I with distance of EEG (a) and TG(b) at different soil layers 
1090

Relationship between GRSP and soil parameters

The relationship between GRSP (EEG or TG) and mycorrhizal colonization can be stimulated by a linearly equation (Fig. 3). The mycorrhizal colonization accounts for the variation of EEG and TG of $19.55 \%$ and $25.85 \%$, respectively. The concentrations of EEG and TG increased 0.1248 and $0.2181 \mathrm{mg} / \mathrm{g}$, respectively when mycorrhizal colonization increases $1 \%$.

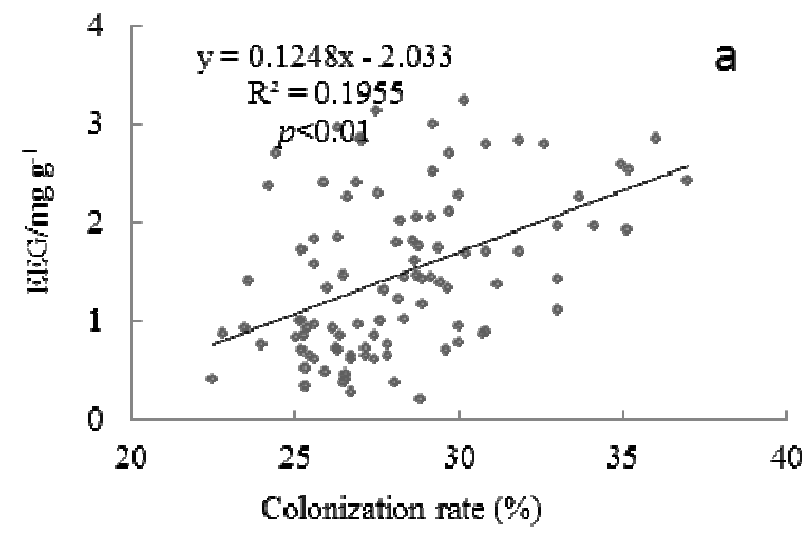

Comparing to mycorrhizal colonization, SOC accounts for more variation of EEG and TG with the explanation rate of $71.76 \%$ and $70.59 \%$, respectively (Fig. 4). EEG and TG presents similar trend with the increase of SOC. The similar trends of EEG and TG are observed with SOC when soil TN is considered (Fig. 5). Further, the explanation degree of soil TN to EEG and TG is almost same, although the increasing rate of EEG and TG is different with the increase of TN.

Fig. 3. The relationship between EEG (a) and TG (b) with colonization rate
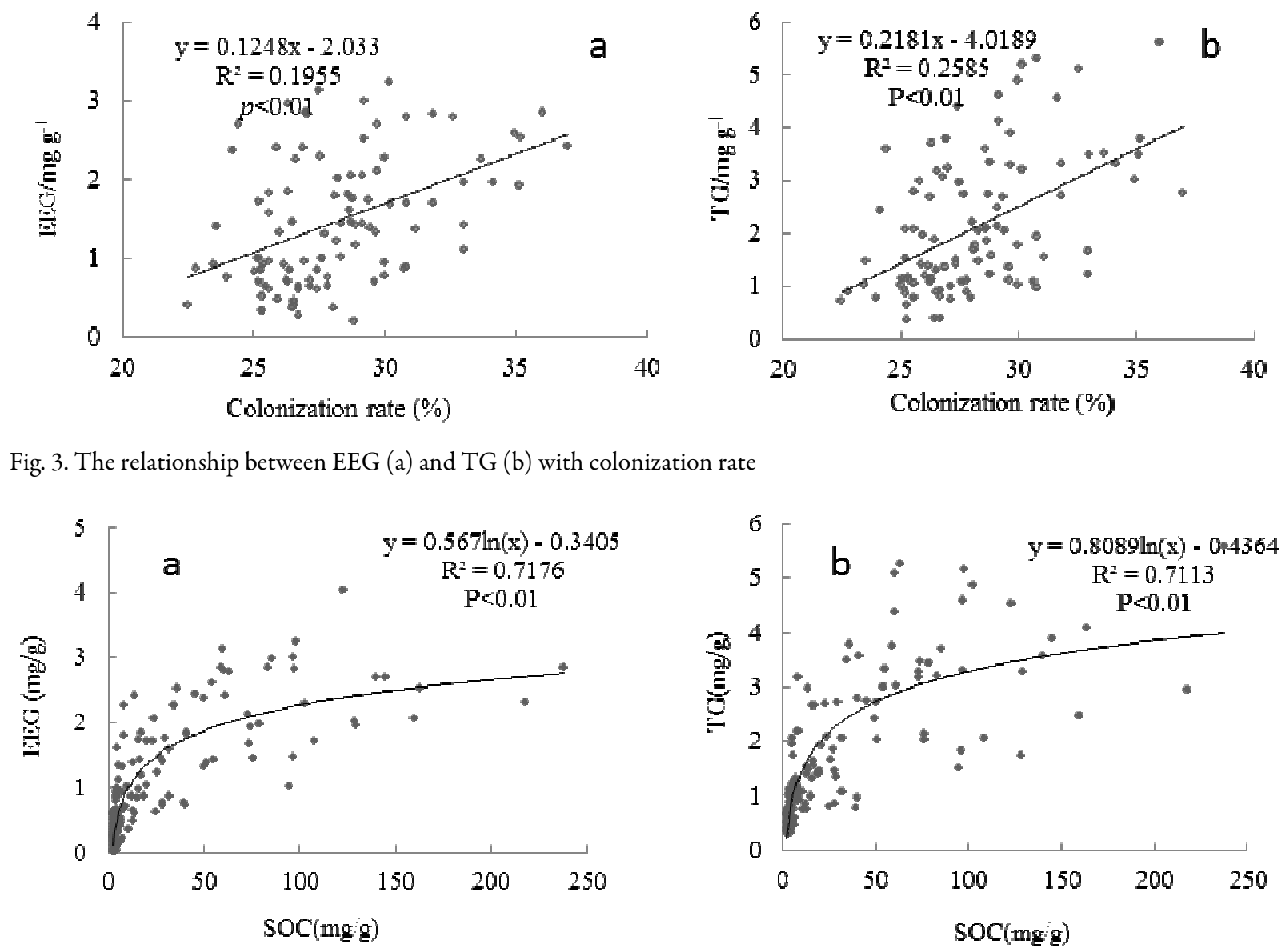

Fig. 4. Relationship between EEG (a) and TG (b) and soil organic carbon (SOC)
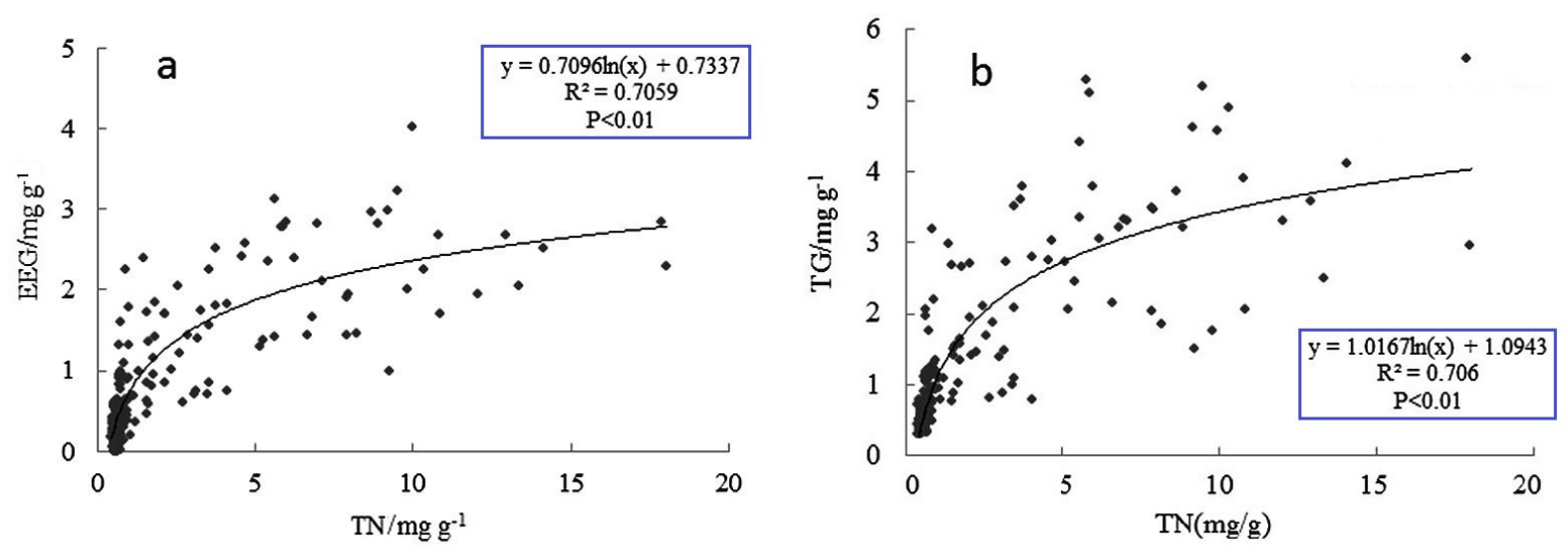

Fig. 5. Relationships between EEG (a) and TG (b) and (TN) 


\section{Discussion}

Spatial autocorrelation is a spatial analysis method commonly used in all kinds of fields, such as environment (Shen et al., 2019), plant diversity (Kim and Shin, 2016), medicine (Akmatov et al., 2018), traffic (Blazquez et al., 2018). Certainly, spatial autocorrelation was usually used to explain the spatial variation of soil characteristics, such as soil moisture (Kim, 2013), soil organic carbon (Liang et al., 2007), soil microbial community (Deakin et al., 2018). Spatial autocorrelation also used in mycorrhizal fungal diversity, such as AMF communities (Horn et al., 2014) and spatial variation (Shi et al., 2013b), but there is little study in GRSP. GRSP as an exclusive organic substance secreted by AMF, which is a main indicator for studying soil carbon pools and nitrogen pools (Jing et al., 2017). Therefore, we studied the spatial distribution of GRSP in soil on temperate forests where hold huge carbon.

Researches have shown that the soil depth has a significant effect on GRSP (Roldan and Salinas, 2007; Wang et al., 2017). In this study, we study the concentration of GRSP (EEG and TG) at a 0-100 cm soil profile, which showed that GRSP exhibited a similar relationship in a shallow $30 \mathrm{~cm}$ soil profile. This finding is consistent with previous studies that exhibited obvious vertical decreasing pattern in a shallow $40 \mathrm{~cm}$ soil profile (Wu et al., 2012; Wang et al., 2017). However, our results showed that no difference was observed both EEG and TG among three soil layers from 40 to $100 \mathrm{~cm}$, which conflicted with the study made by Wang et al. (2017) in farmland. This possible reason is due to the ecological type. The root is shallow in farmland compared to forest, which lead to the rapid decrease of GRSP in deeper soil. Further, this also caused the changes of GRSP according to log function in the current study rather than linear function (Wang et al., 2017). Anyway, the decreasing trend of GRSP with the soil deepening is consistent with previous majority studies (Wang et al., 2017; Wu et al., 2012).

The autocorrelation of soil nutrient parameters, even glomeromycotan family composition has been analyzed (Stürmer et al., 2018). However, this study is the first to explore the autocorrelation of GRSP in different soil depths in our knowledge, although GRSP is an important indicator in the process of driving spatial patterns of natural ecosystems by AMF in different soil depth and climate (Chaudhary et al., 2014). The positive Moran's I presented significant spatial autocorrelation, as the distance increased both for the family composition. Conversely, the negative showed sites tend to present less similarity in GRSP concentration. our result show that there are positive autocorrelation of EEG when the separation distance is less than $4 \mathrm{~m}$ expect $10-20 \mathrm{~cm}$ and $20-30 \mathrm{~cm}$ soil layers (Fig. 3), which indicated the aggregated distribution of GRSP. The similar finding is obtained in TG when the separation distance is less than $4 \mathrm{~m}$ expect $30-50 \mathrm{~cm}$ soil layer.

As the important indicator of the form of symbiotic mycorrhizas between AMF and host plants, mycorrhizal colonization status is usually measured in numerous studies (Wang et al., 2011; Cui et al., 2013; Shi et al., 2017). Our result also suggested that soil GRSP increases with the enhancement of mycorrhizal colonization according to the linear function based on the regression analysis, which is support the previous conclusion drawn by Liu et al. (2013) based on different soil layers of Robinia pseudoacacia plantation on the hilly region of the Loess Plateau. This should tend to be understood because GRSP is a kind of exclusive organic substance secreted by AMF. Many studies have indicated that SOC and TN can affect the concentration of soil GRSP (Wu et al., 2014; Xiao et al., 2019), which is also testified further in this study. Moreover, as a component of SOC, GRSP also affect SOC and TN each other. Zhang et al. (2017) suggested that GRSP probably regulate the resistance of SOC sequestration in tropical forests, especially in the planted and secondary forests. However, Hodge et al. (2001) demonstrated AMF accelerates decomposition and acquires nitrogen directly from organic material, which confirmed that AMF has implications for $\mathrm{N}$ cycling based $\mathrm{N}$ acquisition from organic material. Certainly, the positive correlations between soil $\mathrm{N}$ and GRSP have been testified in previous studies (Fokom $e t$ al., 2013; Wang et al., 2017).

\section{Conclusions}

The concentration of GRSP including EEG and TG decreased with the increase of soil depth according to a logarithmic function. There are not spatial autocorrelation of GRSP in all soil layers. When EEG and TG were considered, the Moran's I coefficient was positive in majority soil layers with the separation distance is less than 4 $\mathrm{m}$. The spatial distribution of GRSP is discrete in typical coniferous and broad-leaved temperate forest and is affected by mycorrhizal colonization rate, SOC and TN.

\section{Acknowledgements}

This study was financially supported by the National NSFC (31670499), Program for Science \& Technology Innovation Talents in Universities of Henan Province (18HASTIT013), Scientific and technological research projects in Henan province (192102110128), Key Laboratory of Mountain Surface Processes and Ecological Regulation, Chinese Academy of Sciences (No.20160618), Laboratory for Earth Surface Processes, Ministry of Education (201612), and Funds for Innovation Research Team in Henan University of Science and Technology (2015TTD002).

\section{Conflict of Interest}

The authors declare that there are no conflicts of interest related to this article.

\section{References}

Akmatov MK, Steffen A, Holstiege J, Hering R, Schulz m, Batzing (2018). Trends and regional variations in the administrative prevalence of attention- deficit/ hyperactivity disorder among children and adolescents in Germany. Scientific Reports 8(1):17029.

Anselin L (1983). Spatial processes-models and applications. Economic Geography 59(3):322-325. 
1092

Baltagi $\mathrm{BH}$ (2005). A companion to theoretical econometrics. Peking University Press 28(3):709.

Blazquez CA, Picarte B, Calderon, JF, Losada F (2018). Spatial autocorrelation analysis of cargo trucks on highway crashes in Chile. Accident Analysis and Prevention 120:195-210.

Chaudhary VB, O'Dell TE, Rillig MC, Johnson NC (2014). Multiscale patterns of arbuscular mycorrhizal fungal abundance and diversity in semiarid shrublands. Fungal Ecology 12:32-43.

Cui XC, Hu JL, Lin XG, Wang FY, Chen RR, WangJH, Zhu JG (2013). Arbuscular mycorrhizal fungi alleviate ozone stress on nitrogen nutrition of field wheat. Journal of Agricultural Science and Technology 15:10431052.

Darcy JL, King AJ, Gendron EMS, Schmidt SK (2017). Spatial autocorrelation of microbial communities atop a debris-covered glacier is evidence of a supraglacial chronosequence. FEMS Microbiology Ecology 93(8). doi:10.1093/femsec/fix095.

Deakin G, Tilston EL, Bennett J, Passey T, Harrison N, FernandezFernandez F, Xu XM (2018). Spatial structuring of soil microbial communities in commercial apple orchards. Applied Soil Ecology 130:1-12.

Du HW, Wang Y, Zhuang DF, Jiang XS (2017). Temporal and spatial distribution characteristics in the natural plague foci of Chinese Mongolian gerbils based on spatial autocorrelation. Infectious Diseases of Poverty 6(1):124.

Fokom R, Mofor CT, Wakam LN, Megapche ELN, Tchameni S, Nwaga D, ... Amvam PHA (2013). Glomalin, carbon, nitrogen and soil aggregate stability as affected by land use changes in the humid forest zone in south Cameroon. Applied Ecology and Environmental Research 11(4):581-592.

Gillespie AW, Farrell RE, Walley FL, Ross ARS, Leinweber P, Eckhardt KU (2011). Glomalin-related soil protein contains non-mycorrhizal-related heat-stable proteins, lipids and humic materials. Soil Biology \& Biochemistry 43(4):766-777.

Godbold DL, Hoosbeek MR, Lukac M, Cotrufo MF, Janssens IA, Ceulemans R (2006). Mycorrhizal hyphal turnover as a dominant process for carbon input into soil organic matter. Plant and Soil 281(12):15-24.

GuoLD (2013). Progress of the function of mycorrhizal fungi in the cycle of carbon and nitrogen. Microbiology/Weishengwuxue Tongbao 40(1):158-171.

He XI, Li YP, Zhao LL (2010). Dynamics of arbuscular mycorrhizal fungi and glomalin in the rhizosphere of Artemisia ordosica Krasch. in Mu Us sandland, China. Soil Biology and Biochemistry 42(8):1313-1319.

Hempel S, Götzenberger L, Kühn I, Michalski SG, Rillig MC, Zobel M, Moora M (2013). Mycorrhizas in the Central European flora: relationships with plant life history traits and ecology. Ecology 94(6):1389-1399.

Hodge A, Campbell CD, Fitter AH (2001). An arbuscular mycorrhizal fungus accelerates decomposition and acquires nitrogen directly from organic material. Nature 413(6853):297-299.

Horn S, Caruso T, Verbruggen E, Rillig MC, Hempel S (2014). Arbuscular mycorrhizal fungal communities are phylogenetically clustered at small scales. ISME Journal 8(11):2231-2242.
Jing X, Sanders NJ, Shi Y, Chu H, Classen AT, Zhao K, ... He JS (2015). The links between ecosystem multifunctionality and above- and belowground biodiversity are mediated by climate. Nature Communications 6:8159.

Kim D (2013). Incorporation of multi-scale spatial autocorrelation in soil moisture-landscape modeling. Physical Geography 34(6):441-455.

Kim D, Shin YH (2016). Spatial autocorrelation potentially indicates the degree of changes in the predictive power of environmental factors for plant diversity. Ecological Indicators 60:1130-1141.

Kohmei K, Satoshi Y, Hirotoshi S, Akifumi ST, Amane H, Hirokazu T (2018). Mycorrhizal fungi mediate the direction and strength of plantsoil feedbacks differently between arbuscular mycorrhizal and ectomycorrhizal communities. Communications Biology 1(1):196.

Kubisch P, Hertel D (2015). Do ectomycorrhizal and arbuscular mycorrhizal temperate tree species systematically differ in root orderrelated fine root morphology and biomass? Frontiers in Plant Science $6: 64$.

Liang ER, Wang XB, Cai DX, Liu, S, Wang Y (2007). Spatial autocorrelation analysis on soil organic carbon distribution in Henan Province. The Journal of AppliedEcology 18(6):1305-1310.

Lin G, Mccormack ML, Guo D (2015). Arbuscular mycorrhizal fungal effects on plant competition and community structure. Journal of Ecology 103(5):12241232.

Liu C, Song XX, Wang L, Wang DL, Zhou XM, Liu J, ... Lin HJ (2016). Effects of grazing on soil nitrogen spatial heterogeneity depend on herbivore assemblage and pre-grazing plant diversity. Journal of Applied Ecology 53(1):242-250.

Liu JL, Zhang LL, Fu Q, Ren GQ, Liu L, Yu P, Tan SY (2018). Spatial variability of soil particle-size distribution heterogeneity in farmland. Transactions of the ASABE 61(2):591-601.

Liu RJ, Li XL (2000). Arbuscular mycorrhiza and its application. Beijing, Science Press.

McGuire KL (2007). Common ectomycorrhizal networks may maintain mono-dominance in a tropical rain forest. Ecology 88(3):567-574.

Öpik M, Zobel M, Cantero JJ, Davison J, Facelli, José M, Hiiesalu I (2013). Global sampling of plant roots expands the described molecular diversity ofarbuscular mycorrhizal fungi. Mycorrhiza 23(5):411-430.

Prescott CE (2010). Litter decomposition: what controls it and how can we alter it to sequester more carbon in forest soils? Biogeochemistry 101(13):133-149.

Rillig MC, Wright SF, Nichols KA, Schmidt WF, Torn MS (2001). Large contribution of arbuscular mycorrhizal fungi to soil carbon pools in tropical forest soils. Plant and Soil 233(2):167-177.

Roldan A, Salinas JR (2007).Soil sustainability indicators following conservation tillage practices under subtropical maize and bean crops. Soil and Tillage Research 93(2):273-282.

Rotter P, Maly S, Sanka O, Sanka M, Cizmar D, Zbiral J, ... Kalabova T (2017). Is glomalin an appropriate indicator of forest soil reactive nitrogen status? Journal of Plant Nutrition and Soil Science 180(6):694 704.

Sadeq M (2016). Spatial patterns and secular trends in human leishmaniasis incidence in morocco between 2003 and 2013. Infectious Diseases of Poverty $5(1): 48$. 
Shen Y,ZhangLP, Fang X (2019). Spatiotemporal patterns of recent PM2.5 concentrations over typical urban agglomerations in China. The Science of the Total Environment 655:13-26.

Shi Z, Chen Y, Hou X, Gao S, Wang F (2013a). Arbuscular mycorrhizal fungi associated with tree peony in 3 geographic locations in China. Turkish Journal of Agriculture and Forestry37(6):726-733.

Shi Z, Wang F, Liu Y (2012). Response of soil respiration under different mycorrhizal strategies to precipitation and temperature. Journal of Soil Science and Plant Nutrition 12(3):411-420.

Shi ZY, Liu DH, Wang FY (2013b). Spatial variation of arbuscular mycorrhizal fungi in two vegetatiob types in gurbantonggut desert. Contemporary Problems of Ecology 20(4):523-533.

Shi ZY, Zhang XI, Xu SX, Lan ZJ, Li K, Wang YM, ... Chen YL (2017). Mycorrhizal relationship in lupines: a review. Legume Research 40(6):965-973.

Steinberg PD, Rillig MC (2003). Differential decomposition of arbuscular mycorrhizal fungal hyphae and glomalin. Soil Biology and Biochemistry 35(1):191-194.

Stürmer S, Oliveira LZ, Morton JB (2018). Gigasporaceae versus Glomeraceae (phylum Glomeromycota): a biogeographic tale of dominance in maritime sand dunes. Fungal Ecology 32:49-56.

Tang HL, Liu L, Wang L, Chao-Jie BA (2009). Effect of land use type on profile distribution of glomalin: effect of land use type on profile distribution of gomalin. Chinese Journal of Eco-Agriculture 17(6):1137-1142.

Urcelay C, Díaz S (2003). The mycorrhizal dependence of subordinates determines the effect of arbuscular mycorrhizal fungi on plant diversity. Ecology Letters 6(5):388-391.

Wang FY, Tong RJ, Shi ZY, Xu XF, He XH (2011). Inoculations with arbuscular mycorrhizal fungi increase vegetable yields and decrease phoxim concentrations in carrot and green onion and their soils. PLoS One 6(2):e16949.

Wang B, Qiu YL (2006). Phylogenetic distribution and evolution of mycorrhizas in land plants. Mycorrhiza 16(5):299-363.

Wang Q, Lu HL, Chen JY, Hong HL, Liu JC, Li JW, Yan CL (2018). Spatial distribution of glomalin-related soil protein and its relationship with sediment carbon sequestration across a mangrove forest. Science of the Total Environment 613:548-556.
Wang W, Zhong Z, Wang Q, Wan H, Fu Y, He X (2017). Glomalin contributed more to carbon, nutrients in deeper soils, and differently associated with climates and soil properties in vertical profiles. Scientific Reports 7(1):13003.

Wright SF, Green VS, Cavigelli MA (2007). Glomalin in aggregate size classes from three different farming systems. Soil \& Tillage Research 94(2):546-549.

Wright SF, Upadhyaya A (1998a). A survey of soils for aggregate stability and glomalin, a gycoprotein produced by hyphae of arbuscular mycorrhizal fungi. Plant and Soil 198(1):97-107.

Wright SF, Upadhyaya A, Buyer JS (1998b). Comparison of N-linked oligosaccharides of giomalin from arbuscular mycorrhizal fungi and soils by capillary electrophoresis. Soil Biology and Biochemistry 30(13):18531857.

Wu QS, He XH, Zou YN, He KP, Sun YH, Cao MQ (2012). Spatial distribution of glomalin-related soil protein and its relationships with root mycorrhization, soil aggregates, carbohydrates, activity of protease and $\beta$-glucosidase in the rhizosphere of citrus unshiu. Soil Biology and Biochemistry 45:181-183.

Wu QS, Wang S, Cao MQ, Zou YN, Yao YX (2014). Tempo-spatial distribution and related functionings of root glomalin and glomalinrelated soil protein in a citrus rhizosphere. Journal of Animal and Plant Sciences 24(1):245-251.

Xiao L, Zhang Y,LiP, Xu GC, ShiP,ZhangY(2019). Effects of freeze-thaw cycles on aggregate-associated organic carbon and glomalin-related soil protein in natural-succession grassland and Chinese pine forest on the Loess Plateau. Geoderma 334:1-8.

Yang Y,Dou YX, Liu D, An SS (2017). Spatial pattern and heterogeneity of soil moisture along a transect in a small catchment on the Loess Plateau. Journal of Hydrology 550:566-477.

ZhangJ, Tang X,ZhongS, Yin G, Gao Y, He X(2017). Recalcitrant carbon concentrations in gomalin-related soil protein facilitate soil organic carbon preservation in tropical forests. Scientific Reports 7(1):2391. 